\title{
Use of LTPP Data to Quantify Moisture Damage under Crack Sealing and Surface Treatments in Asphalt Pavements
}

\author{
Momen R. Mousa, Mostafa A. Elseifa*, and Mohammed Z. Bashar \\ Department of Civil and Environmental Engineering, Louisiana State University, Baton Rouge, LA 70803
}

\begin{abstract}
Crack sealing and seal coats are used to prevent the ingress of water into the pavement, thus delaying its deterioration. Yet, earlier studies indicated that sealing pavements in areas with high ground water table (GWT) prevented moisture from escaping upwards through the cracks of asphalt pavements, therefore, accelerating stripping. The objectives of this study were to determine whether these treatments contribute to stripping in Asphalt Concrete (AC) and/or moisture accumulation in the base and to evaluate the effect of GWT, rain, and traffic on subsurface failures under these treatments. In this study, nine test sections included in the Long-Term Pavement Performance (LTPP) program and several field chip seal projects in Louisiana were analyzed. Results indicated that these treatments do not contribute to stripping. However, the cause of common stripping under these treatments in the Southern United States is moisture entrapment under the AC layer under shallow GWT conditions, which is also the key contributor to stripping under unsealed sections.
\end{abstract}

\section{Introduction}

Preventive maintenance techniques, including crack sealing and seal coats, are commonly used to improve the functional conditions of asphalt pavements. If applied correctly and timely, these treatments may reduce pavement deterioration by minimizing the infiltration of water into the pavement structure; thus, extending pavement service life [1]. Yet, concerns exist that these treatments may be responsible for subsurface failures if the surrounding moisture conditions are not adequately considered. Subsurface failure refers to the stripping of the layer treated with crack sealing or seal coat due to entrapped water and/or water vapor especially in regions with shallow Ground Water Table (GWT). Therefore, the primary objectives of this study were to (a) determine whether crack sealing and seal coats contribute to stripping in the AC layer and/or moisture accumulation in the base layer; and (b) evaluate the effect of GWT, rain, and traffic on the subsurface failures under these treatments. These objectives were achieved by analyzing AC test sections included in the Long-Term Pavement Performance (LTPP) program as well as analyzing chip seal sections in Louisiana.

\section{Background}

\subsection{Moisture damage under crack sealing and seal coats}

As early as 1949, McKesson [2] highlighted the detrimental effects of seal coats constructed on roadways with shallow GWT levels. Under such conditions, the seal coat developed a vapor seal causing blistering in AC pavements. In 1985, Kennedy [3] supported McKesson's [2] hypothesis, and reported that surface sealing could prevent the evaporation of water that moves upwards through the pavement [3]. This conclusion was based on numerous sections in Texas and other states, in which stripping was observed under existing AC pavements after receiving a surface seal. Similar findings were reported in Colorado and Nebraska, as they noticed stripping in $\mathrm{AC}$ layers due to water trapped underneath seal coats [4]. A research study was conducted in Minnesota to evaluate the factors associated with stripping in AC pavements under chip-seal treatments. Based on a state survey, 26\% of the respondents reported stripping as a major issue for their chip-sealed pavements [5]. The Federal Highway Administration (FHWA) sponsored a research study to evaluate the benefits of preventive maintenance treatments and to develop application processes for these treatments. One of the major findings of this research indicated that sealing cracks while there is moisture inside the pavement structure can accelerate stripping [6]. While most of these studies reported stripping under surface treatments, there are still several gaps in knowledge and practice. Therefore, this study evaluated stripping under crack sealing and seal coats and their relationship to the most relevant contributing factors.

\footnotetext{
* Corresponding author: elseifi@1su.edu
} 


\subsection{LTPP database}

To evaluate moisture damage under crack sealing and seal coats in this study, a critical challenge was to collect a data set documenting moisture-related problems in the treated test sections along with the contributing factors to this damage. Therefore, all the modules in the LTPP database were reviewed and the maintenance (MNT), materials testing (TST), Seasonal Monitoring Program (SMP) modules were identified as the best available source to meet the objectives of this study. MNT contains data reported by highway agencies on maintenance treatments applied to test sections. TST module includes results of visual examination of AC cores to observe the core properties such as stripping. SMP has Time Domain Reflectometry (TDR) installed at different depths in the unbound layers of many sites to determine their subsurface moisture contents. Furthermore, the LTPP SMP uses observation wells to determine if the depth of the water table is within approximately $5 \mathrm{~m}$ of the pavement surface. Other modules used in this study included the Administration, Climate, and Traffic modules [7].

\section{LTPP data collection}

\subsection{LTPP test sections selection criteria}

Of particular interest was the data assessment of LTPP test sections that (1) were treated with crack sealing or seal coat without further treatments for at least five years after the treatment date; (2) have available GWT data within the first five years following the treatment date; and (3) have extracted cores before and after the treatment date. This specific selection criteria resulted in four crack-sealed \& five seal-coated LTPP test sections.

\subsection{Collected data for the selected LTTP test sections}

The collected data were obtained from the LTPP database standard release 30.0. Multiple data buckets for desired variables were downloaded using online
Infopave ${ }^{\circledR}$ features. Table 1 summarizes the collected data for the 9 selected test sections in this study.

\subsection{Evaluation of stripping in extracted cores}

As previously mentioned, each extracted core was assigned 4 to 6 numeric codes related to the observed properties of the core. Unfortunately, for the same core, these codes differed significantly due to the subjective visual evaluation by the inspectors making it difficult to decide whether stripping occurred in a test section given that at least 10 cores were extracted from each section. Therefore, in this study, to quantitatively determine whether a specific section is stripped; considering all the reported codes, the probability of stripping $\left(\mathrm{P}_{t}\right)$ was calculated before and after the treatment date as follows:

$$
\mathrm{P}_{\mathrm{t}}(\%)=\frac{\mathrm{s}}{\mathrm{n} * \mathrm{i}} * 100
$$

where $t$ is the time (years) before or after the treatment date $(\mathrm{t}=$ core date-treatment date); $\mathrm{n}$ is the number of cores extracted from the section at time $t ; i$ is the number of inspectors at time $t$; and $s$ is the total number of reported codes related to stripping (codes 4, 7, 10, 14, 18, and 19) at time t.

\subsection{Evaluation of moisture accumulation in the base layer}

To evaluate whether crack sealing and seal coat contributed to moisture accumulation in the base layer, the average change in TDR moisture content in the base $(\triangle \mathrm{MC})$ was calculated as follows:

$$
\Delta \mathrm{MC}=\mathrm{MC}_{\mathrm{f}}-\mathrm{MC}_{\mathrm{i}}
$$

where $\mathrm{MC}_{\mathrm{f}}$ and $\mathrm{MC}_{\mathrm{i}}$ are the average $\mathrm{TDR}$ Moisture contents in the base layer after and before treatment, respectively. For accurate comparison, for the same test section, $\mathrm{MC}_{\mathrm{f}}$ and $\mathrm{MC}_{\mathrm{i}}$ were calculated over the same time period and TDR depth. Positive values indicate that the amount of water in the base layer increased after treatment application.

\begin{tabular}{|c|c|}
\hline Data & Description \\
\hline Section ID & Consists of the state code followed by SHRP ID \\
\hline Date of treatment & - \\
\hline Total avg. annual rain $(\mathrm{mm})$ & Summation of average annual rain over a period of 5 years after the treatment date \\
\hline \multirow{2}{*}{ Avg. AADT (Vehicles/day) } & $\sum$ AADT for a period of 5 years after treatment date \\
\hline & 5 \\
\hline Avg. GWT (m) & Average GWT for a period of 5 years after treatment date. \\
\hline $\begin{array}{l}\text { Avg. TDR Moisture content } \\
\text { in the base layer }(\%)\end{array}$ & $\begin{array}{l}\text { This average value was calculated before and after the treatment date (i) at exactly the same TDR } \\
\text { depth; and (ii) over the same time period. This time period was less than } 5 \text { years due to limited } \\
\text { measurements. }\end{array}$ \\
\hline Asphalt core codes & $\begin{array}{l}\text { Multiple cores were extracted from each section before and after treatment date. Each core was } \\
\text { visually examined by } 4 \text { to } 6 \text { inspectors. Each inspector reports a code ranging between } 1 \text { and } 61 \text { that } \\
\text { describes the core's physical condition. }\end{array}$ \\
\hline Total cracking $\%$ in $\mathrm{AC}$ & This percentage was collected for each section for a period of 5 years following the treatment date. \\
\hline
\end{tabular}

Table 1. Summary of the collected data. 


\section{Analysis of results for the cracked- sealed sections}

\subsection{Contribution of crack sealing to moisture damage in the ac layer}

Figure 1 presents $\mathrm{P}_{\mathrm{t}}$ before and after crack sealing for the four crack sealed test sections. As shown, all the test sections did not show any signs of stripping before crack sealing as indicated by $\mathrm{P}=0$ at negative values of $\mathrm{t}$. After crack sealing, sections 25-1002 and 56-1007 did not experience any stripping after 1.4 and 8.4 years, respectively, indicating that crack sealing did not contribute to moisture damage in these sections. On the other hand, sections 27-6251 and 9-1803 experienced a slight increase in stripping probability after 2.7 and 8.1 years, respectively. Yet, this stripping could be considered insignificant because $\mathrm{P}_{\mathrm{t}}$ did not exceed 20\% in both sections. Based on this analysis, it may be concluded that crack sealing had negligible contribution to moisture damage in $\mathrm{AC}$ in these test sections irrespective of other factors such as traffic, rain, and GWT. The effects of these factors were analyzed to determine their correlation to moisture damage as shown in Table 2.

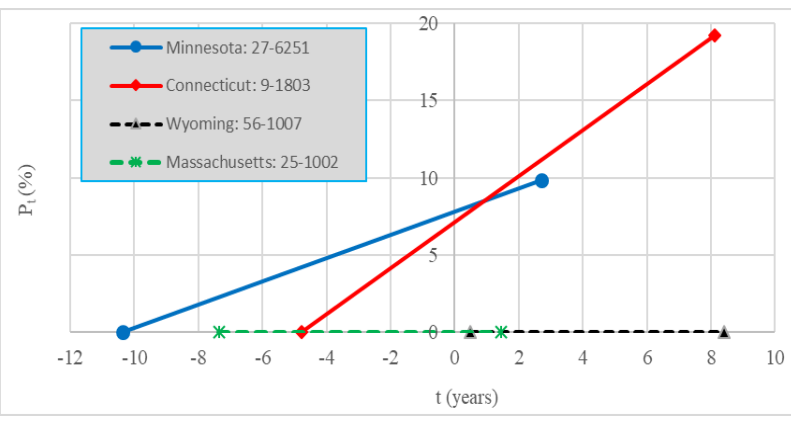

Fig. 1. Probability of stripping before and after crack sealing for the four test sections.

To evaluate the effects of the considered factors on moisture damage in AC, the Stripping Rate (SR) was calculated as the slope of the lines in Figure 1. The SR values in Table 2 indicate that a stripping potential was observed when the GWT was about $2 \mathrm{~m}$ for sections 276251 and 9-1803. When the GWT was greater than $5 \mathrm{~m}$ (DEEP) for the other two sections, there was no stripping potential. Comparing the precipitation and traffic data against the SR values did not show noticeable relation. For instance, section 25-1002 had the highest AADT and second highest total average annual rain but zero SR. These results suggest that although crack sealing did not seem to cause a significant increase in stripping potential, the SR under shallow GWT was relatively higher than the SR under deep GWT.
Table 2. Summary of collected and calculated data for the crack sealed test sections.

\begin{tabular}{|c|c|c|c|c|}
\hline Section ID & $27-6251$ & $9-1803$ & $56-1007$ & $25-1002$ \\
\hline $\begin{array}{c}\text { Average } \\
\text { GWT (m) }\end{array}$ & 2.0 & 1.6 & DEEP & DEEP \\
\hline $\begin{array}{c}\text { Total average } \\
\text { annual rain } \\
\text { (mm) }\end{array}$ & 3,609 & 6,015 & 1,453 & 5,469 \\
\hline $\begin{array}{c}\text { Average } \\
\text { AADT } \\
\text { (Vehicles/day) }\end{array}$ & 3,543 & 5,010 & 874 & 7,991 \\
\hline SR (\%/year) & 0.8 & 1.5 & 0 & 0 \\
\hline DMC (\%) & +0.5 & +0.2 & - & -1.7 \\
\hline $\begin{array}{c}\text { P-value of } \\
\text { T-test }\end{array}$ & 0.44 & 0.61 & - & 0.05 \\
\hline
\end{tabular}

\subsection{Contribution of crack sealing to moisture accumulation in the base layer}

As shown in Table 2, sections 27-6251 and 9-1803 (shallow GWT) had positive values of $\triangle \mathrm{MC}$ indicating that there was slight accumulation of moisture in the base layer. Yet, conducting t-test between the TDR Moisture contents before and after crack sealing indicated that the difference is insignificant for both sections as indicated by the high P-values in Table 2. Section 25-1002 (deep GWT) had negative $\triangle \mathrm{MC}$ indicating that crack sealing reduced the amount of moisture reaching the base, and the corresponding low P-value indicated that this difference is significant. Interestingly, this section had the highest average AADT and second highest total average annual rain indicating that moisture accumulation in the base is more controlled by the GWT level. To capture the effects of traffic on crack sealing performance, the total cracking percentage in AC after five years of crack sealing was plotted against the average AADT for the four test sections, see Figure 2. As shown, sections with higher traffic experienced more surface cracking. This indicates that traffic has more significant impact on surface cracking, rather than subsurface failures in crack-sealed AC pavements.

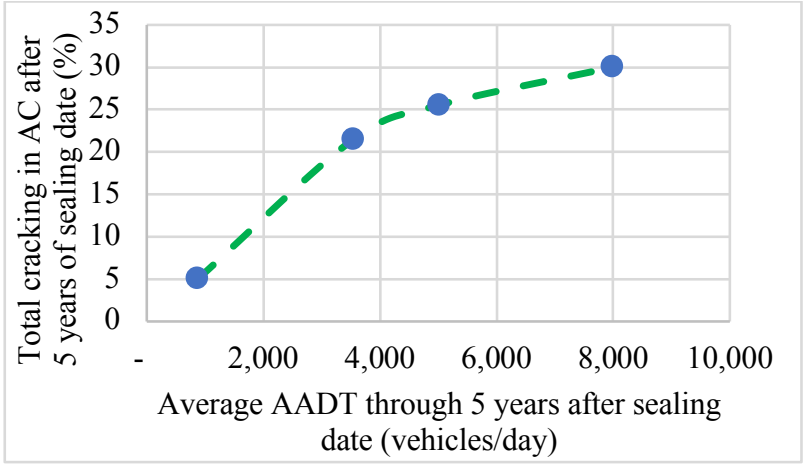

Fig. 2. Total cracking percentage after 5 years of sealing date for the four test sections. 


\section{Analysis of results for sections treated with seal coat}

\subsection{Contribution of seal coat to moisture damage in the asphalt layer}

Similar analyses were conducted for the seal-coated test sections. Figure 3 presents $\mathrm{P}_{\mathrm{t}}$ before and after seal coat for the five seal-coated test sections. Sections 13-1031, 49-1001, and 30-114 did not experience any moisture damage in AC after significant time of sealant application. Section 48-3739 experienced slight stripping after 3.7 years $\left(\mathrm{P}_{3.7}=17 \%\right)$. Section $48-1068$ had the highest $\mathrm{P}_{t}$ after sealant application indicating that it is highly susceptible to moisture damage. Yet, this could not be attributed to sealant application since this section showed relatively significant stripping before sealant application $\left(\mathrm{P}_{-3}=12 \%\right)$.

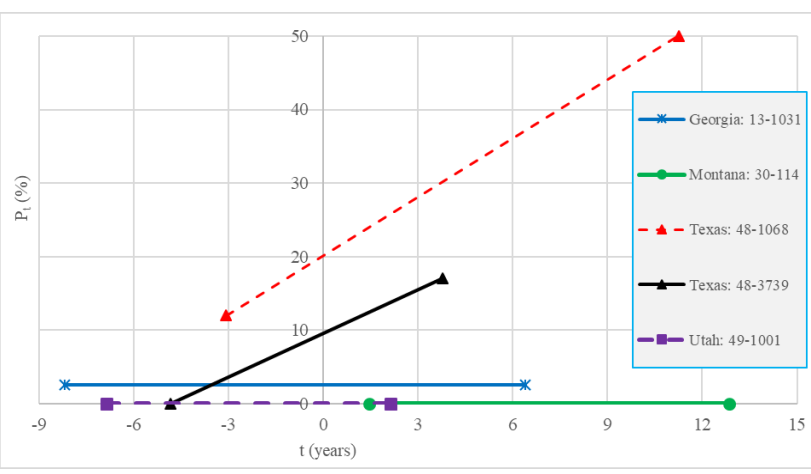

Fig. 3. Probability of stripping before and after seal coat for the five test sections.

Table 3 summarizes the GWT, precipitation, and traffic data for the test sections. Comparing the precipitation and traffic data against the SR values did not show noticeable trend. The SR was more related to the GWT depth. Sections 13-1031, 30-114, and 49-1001 had deep GWT and zero SR. When the average GWT was almost $4 \mathrm{~m}$ for sections $48-1068$ and 48-3739 in Texas, the SR was maximum. Yet, it seems that seal coats are not the primary reason for this relatively high SR because in section 48-1068, stripping existed before sealant application. Therefore, it could be established that shallow GWT accelerates moisture damage in AC whether the pavement surface is sealed or not due to moisture entrapment under the AC layer itself. This conclusion agrees with previous studies reporting that moisture may get entrapped beneath the AC overlays [8, 9]. This conclusion also agrees with a previous study in Texas, which reported that stripping is a major problem throughout Texas, primarily in areas with shallow GWT [10].

\subsection{Contribution of seal coat to moisture accumulation in the base layer}

All the three $\triangle \mathrm{MC}$ in Table 3 showed positive values regardless of the GWT, average ADT, or average annual rain. Based on the P-values of the t-test, these differences were significant for two out of the three sections. This generally indicates that in all the cases, seal coats contributed to moisture accumulation in the base layer, probably by reducing the amount of water evaporating from the pavement surface.

Table 3. Summary of collected and calculated data for the sealcoated test sections.

\begin{tabular}{|c|c|c|c|c|c|}
\hline Section ID & \begin{tabular}{|l|}
$13-1031$ \\
\end{tabular} & $30-114$ & 48-1068 & 48-3739 & 49-1001 \\
\hline $\begin{array}{c}\text { Avg. GWT } \\
\text { (m) }\end{array}$ & DEEP & DEEP & 4.21 & 4.05 & DEEP \\
\hline $\begin{array}{l}\text { Total avg. } \\
\text { annual rain } \\
(\mathrm{mm})\end{array}$ & 7,056 & 2,007 & 6,139 & 3,363 & 916 \\
\hline $\begin{array}{c}\text { Avg. AADT } \\
\text { (Vehicles/day) }\end{array}$ & 4,608 & 1,823 & 2,101 & 2,975 & 998 \\
\hline SR (\%/year) & 0.01 & 0.00 & 2.6 & 1.9 & 0.00 \\
\hline$\Delta \mathrm{MC} \mathrm{( \% )}$ & 6.1 & - & - & 0.5 & 3.4 \\
\hline $\begin{array}{c}\text { P-value of } \\
\text { T-test }\end{array}$ & 0.13 & - & - & 0.03 & 0.004 \\
\hline
\end{tabular}

\section{Moisture damage in chip-sealed asphalt sections in Louisiana}

The previous results are only limited to the 9 LTPP sections considered in this study. To complement these results, the research team further analyzed moisture damage in $\mathrm{AC}$ under field chip seal projects located in the Southern United States in Louisiana, where stripping is a major problem [10]. In this analysis, 2,733 core reports obtained from the Louisiana Department of Transportation and Development (LaDOTD) throughout the nine districts in Louisiana, were analyzed. Out of these cores, 2,169 cores were extracted from unsealed $\mathrm{AC}$ pavement sections, while the remaining 564 cores were extracted from chip sealed AC pavement sections. Trained personnel visually inspected all of the 2,733 cores to identify stripped cores, and then categorized all the cores based on the district number, treatment type (chip-sealed or unsealed), and conditions (stripped or non-stripped). Figure 4 presents the percentage of stripped cores for each treatment type in all the districts.

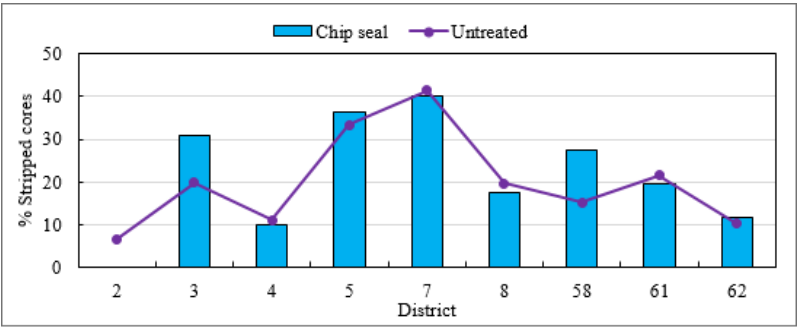

Fig. 4. Extent of moisture damage in different districts of Louisiana.

The trends in Figure 4 indicate that the percentage of stripping in chip-sealed sections is almost similar to that of the unsealed sections. Based on these results, one may conclude that application of chip seal does not seem to contribute to moisture damage. Another key observation from Figure 4 is that stripping, whether in chip-sealed or 
unsealed sections, is dependent on the geographic location. For example, District 7, which is generally characterized by its shallow GWT had the highest percentage of stripped cores for chip-sealed and unsealed sections. This observation suggests that shallow GWT could contribute to moisture damage in AC pavements in general (sealed or unsealed) due to moisture entrapment under the AC layer. Such conclusion agrees with conclusions drawn from the aforementioned analysis of seal-coated LTPP sections.

\section{Conclusions}

The objective of this study was twofold. First, to determine whether crack sealing and seal coats contribute to moisture damage in the $\mathrm{AC}$ layer and/or moisture accumulation in the base layer. Second, to evaluate the effects of GWT, rain, and traffic on the subsurface failures under these treatments. To achieve these objectives, the research team analyzed nine test sections included in the LTPP program and several field chip seal projects in Louisiana. For crack sealing projects, for all GWT conditions, stripping was insignificant or negligible. These results were applicable regardless of precipitation or traffic levels. Traffic had more significant impact on surface cracking, rather than subsurface failures in crack-sealed AC pavements. For the seal coated sections, seal coats seemed to trap moisture in the base layer under all the GWT, precipitation, and traffic conditions, possibly by reducing the amount of water evaporating from the pavement surface. Yet, the entrapment effect of seal coats did not contribute to moisture damage in $\mathrm{AC}$ layer. Instead, moisture damage in $\mathrm{AC}$ is accelerated under shallow GWT conditions, whether the pavement surface is sealed or not due to moisture entrapment under the AC layer itself.

\section{Recommendations}

The results of this study indicated that crack sealing and seal coats do not significantly contribute to the stripping behavior in AC. However, the overwhelming cause of stripping under these treatments, particularly chip seal, in the Southern United States is "moisture entrapment under the AC itself under shallow GWT conditions" which is also the key contributor to stripping under unsealed sections. Therefore, proper subsurface drainage is essential in AC pavements, particularly in regions with shallow GWT, to reduce the probability of saturated subbase and base layers, which will reduce the amount of moisture in AC layer. Furthermore, it is advisable to evaluate the existing material for stripping susceptibility before $\mathrm{AC}$ overlay or surface treatment application even if there is no evidence of current stripping. Moreover, it is highly recommended to select extended dry periods to apply AC overlays or surface treatments. Before application, it is preferred to measure the initial saturation (or moisture content) of the original pavement to ensure that the existing moisture is minimal.

\section{References}

1. Lee, J., Hastak, M., and Ahn, H.J. (2015). Crack Sealing and Filling: Best Practices.

2. McKesson, C.L. (1949). Slippery Pavements Causes and Treatments, Proc. Assoc. of Asphalt Paving Technologists, Vol. 18.

3. Kennedy, T. W. (1985). Prevention of water damage in asphalt mixtures, STP 899, American Society for Testing and Materials, 119-133, Philadelphia.

4. Johnson, D.R., and Freeman, R.B. (2002). Rehabilitation techniques for stripped asphalt pavements. No. FHWA/MT-002-003/8123.

5. Rettner, L.D., and Tompkins, D. (2017). Prevention of Stripping Under Chip Seals. No. MN/RC 2017-35. Minnesota Department of Transportation, Research Services and Library.

6. Zaniewski, J.P., and Mamlouk, M.S. (1996). Pavement Maintenance Effectiveness -Preventive Maintenance Treatments. PARTICIPANT'S HANDBOOK. No. FHWA-SA-96-027.

7. Elkins, G.E., Thompson, T., Ostrom, B., and Visintine, B. (2018). Long-term pavement performance information management system: Pavement performance database user reference guide. No. FHWA-RD-03-088 (revision). Turner-Fairbank Highway Research Center.

8. Kandhal, P.S., Lubold, C.W., and Roberts, F.L. (1989). Water damage to asphalt overlays: case histories. No. NCAT Report No. 89-1. Nashville, Tennessee: National Center for Asphalt Technology.

9. Benjamin, A., Rejaseker, L., and Akhavan, R. (2007). Forensic Investigation of Pavement Failure on Vasquez Boulevard. No. CDOT-2007-7. Colorado Department of Transportation, Research Branch.

10.Kennedy, T., and Anagnos, J.N. (1984). Techniques for Reducing Moisture Damage in Asphalt Mixtures. No. FHWA-TX-85-68+ 253-9F. Center for Transportation Research, Bureau of Engineering Research, University of Texas at Austin. 